\begin{tabular}{ccc}
\hline & International Journal of Engineering \& Technology, $7(2.12)(2018) 124-127$ \\
SPC & International Journal of Engineering \& Technology \\
Website: $w w w . s c i e n c e p u b c o . c o m / i n d e x . p h p / I J E T$ & Research Paper \\
\hline
\end{tabular}

\title{
Development of control device for digital permanent equipment capable of temperature control in each rod
}

\author{
Yong-MoKim* \\ Dept. of Visual Image Design,277Hyodeok-ro, Gwangju University, Nam-guGwangju city, 61743 , KOREA \\ *Corresponding author E-mail: Mdc2000@gwangju.ac.kr
}

\begin{abstract}
Background/Objectives: Digital permanent equipment is one of essential beauty treatment devices in beauty parlors. About 30 thousand of beauty parlors have been launching a startup every year. Needs of diverse hair style by a wide range of customers have become increasing and importance of digital permanent equipment is also increased.

Methods/Statistical analysis: Digital permanent equipment is possible to control temperature at each rod. Reliability of parts which is used in circuit and product certification is so important that evaluation of reliability as well as product certification is implemented.

Findings: Control devices such as power supply for rod, temperature setting for rod, and distribution module to control temperature in each module which generates control signal of heater and sensor in rod are developed not only to improve the convenience of permanent work that is controlled rod temperature by group unlike conventional products but also to allow with checking fault signal of each rod by an over current. Degree of precision for temperature control has greatly increased to utilize temperature sensor.

Improvements/Applications: Prototype of digital permanent equipment which is able to control temperature of each rod is developed. Plans for reducing costs and increasing capacity through not only modularity of all circuitsbut development of control board with stabilityguaranteed is implemented in this study.
\end{abstract}

Keywords: Temperature Control; Firmware; Rod; Digital Permanent Equipment; Distribution Module; Ozone

\section{Introduction}

Digital permanent equipment is an essential beauty instrument at a hair saloon. Each year the number of new start up hair saloon is around 30,000 and the equipment is purchased. Wide range to suit different customer needs of hair style is increasing and consequently the importance of digital permanent equipment is also increased. The development of digital devices is therefore essential to be able to select various treatment by the variety of hair condition. Several small business in Korea produce and sell the equipment but compared to other developed nations, the reality is a lack of degree of precision and reliability in products [1], [2]. The larger expansion of temperature range than an existing equipment makes it possible for beginner to treat easily according to the extent of the hair damage in this study. Error between real temperature on rod and user's setting temperature is minimized to attach temperature sensor so as to increase the degree of temperature control precision above developed nations level. The conventional products have heating temperature uniformly in whole rods. But its practices resulted in lower customers' satisfaction because there are many cases not to provide desired results in curl as winding hair condition of rod, amount of permanent wave, and hair condition differ from person to person [3], [4]. Also there many cases not to heat in rod due to bad cable connection between digital perm equipment and rods. It causes inconvenience for users on existing products to have to check not only preheating rods but also its condition in the middle of working. Perm performance of digital permanent equipment which is able to control temperature by group is able to be improved so as to not only increase a convenience as well as an effectiveness of getting perm work but also be able to notify a customer of situation automatically checked in case of bad connection between cable and rod. The possibility of market share will be increased through the development of improved performance in this product for increasing the reliability as well as the customers' satisfaction that makes it possible for user to get a perm. Therefore, the core technology of a control and a reliability for digital perm equipment must to be secured [5], [6].

\section{State of domestic and foreign technology}

\subsection{World-class technology level}

Ohiro in Japan makes rod heating itself uniformly distributed over hair on the insidenot only to prevent stains occurred by heat but to make rod size of curl in a different wayof method to apply heat outside like an existing activator machine. Forming a curl in dry condition makes beautiful curl when the hair is dry unlike traditional wet wave. Ohiro digital permanent equipment not only has a general heat treatment function but has ozone neutralization features. $\mathrm{PH}$ balance is controlled to eliminate the residuals remain in alkali element while oxidizing power increases in case of neutralizing ozone 7,8 . 


\subsection{Domestic technology level}

Small and midsize several manufacturers of beauty treatment equipment in Korea are selling digital permanent equipment. OEM method which is designed in Korea, while it is manufactured in China is preferred due to the problem of the unit cost of production. Korea ranks No. 1 in sales, Create Co., Ltd,

has releaseda digital permanent equipment named wave master. Wave master is able to set the temperature as well as the time span according to hair condition and strengthen hair elasticity due to cooling fan installed on the top of the body to provide quick cooling heat. But it has some flaws that temperature setting in each rod is difficult and there is no function to warn bad connection of rods [9], [10].

\section{Research and development}

\subsection{Design and manufacture of control board}

\subsubsection{Control board design}

Control board is composed of a main module not only for setting of rod temperature but for control each rod, and a distribution module which is connected several rods that came off the main module. Temperature control section which receives temperature detecting each of their signals from temperature sensor installed in each rods is generating control signal to maintain the desired heater temperature in each rods done by user. Alarm generator also indicates if an abnormal operation is detected due to short circuit current supplied rods after the measuring amount of current which is supplied distribution module. Distribution module receives power for operation and distributes each rods and temperature control signal to maintain the desired temperature in main module by heater are output to heater as temperature detecting signal is received sensor installed in rods. Block diagram of control board in the digital perm equipment is shown in Figure 1.

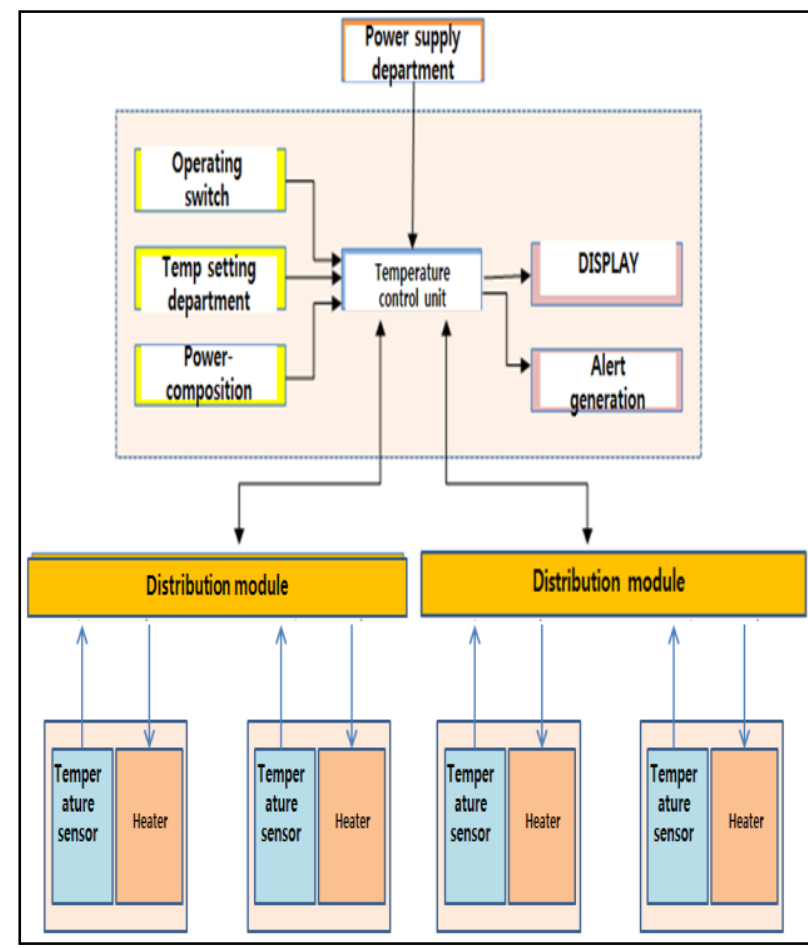

Fig. 1: Block Diagram of Control Board in Digital Perm Equipment.

\subsubsection{Hardware design of control device in digital permanent equipment}

Liner power with $\mathrm{AC} 220 \mathrm{~V} / 60 \mathrm{~Hz}$ is used and temperature control at each rod will be from $40^{\circ} \mathrm{C}$ to $130^{\circ} \mathrm{C}$ at $5^{\circ} \mathrm{Cintervals}$. Time of cycle is up to 30 minutes at one minute intervals. Block diagram of temperature control circuit is shown in Figure 2.

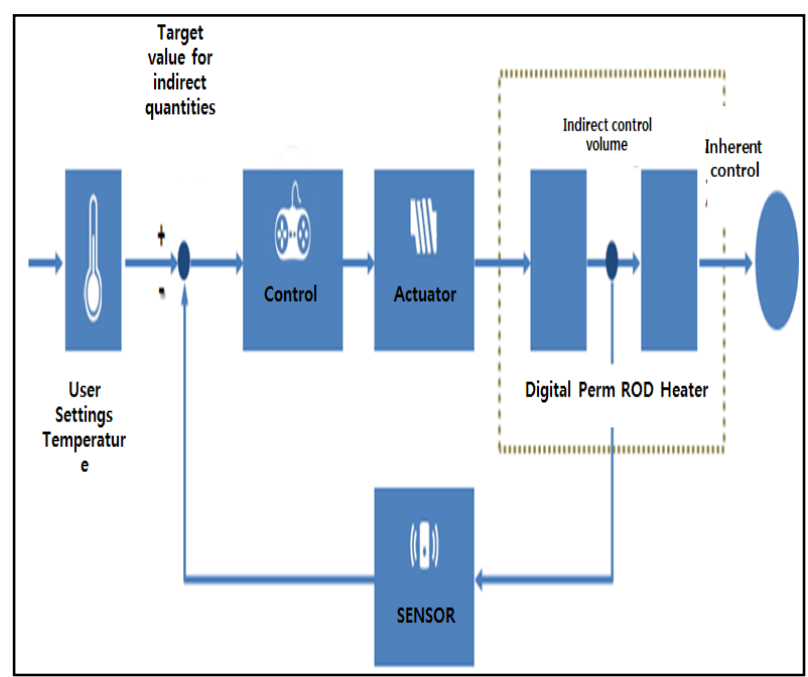

Fig. 2: Block Diagram of Temperature Control Circuit.

MCU in main controller is designed using Cortex-A series and configuration of display screen is shown in figure 3 . It is composed of LED which is verifying rod contacting, adjustable time and its display, contact switch capable of regulating time and temperature, contact switch capable of regulating whole or group temperature, and temperature display screen.

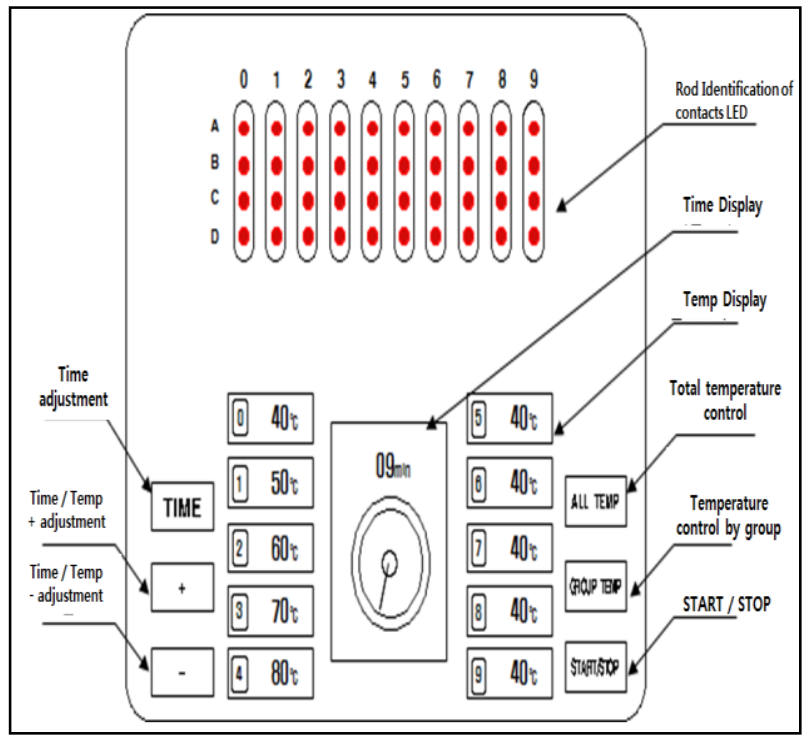

Fig. 3: Screen Configuration of Display Part.

\subsubsection{Design and manufacture of distribution module}

One for each power line and data line is sent distribution module from main module and power line and data line at each rod are connected in each distribution module. Result of distribution model modeling is shown in Figure 4. 


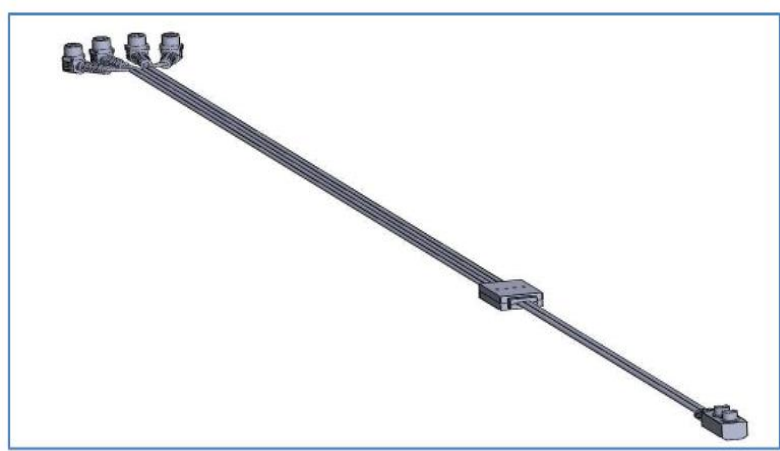

Fig. 4: Modeling Result of Distribution Module.

\subsection{Development of detailed circuit diagram and PCB artwork}

JTAG interface is connected to host computer to test operation of connection between external interface and sensor. JTAG interface is connected to host computer and RS-232C 2port is connected to COM port of host computer. Sensor and circuit is used LM35DZ and AMP(LM324) while external AC/DC adaptor is used connector of power connection with 5 voltage. PCB artwork using PADs is adopted two sided board FR4. Circuit diagram of digital perm power is shown in Figure 5 and fabrication result of LCD display is shown in Figure 6.

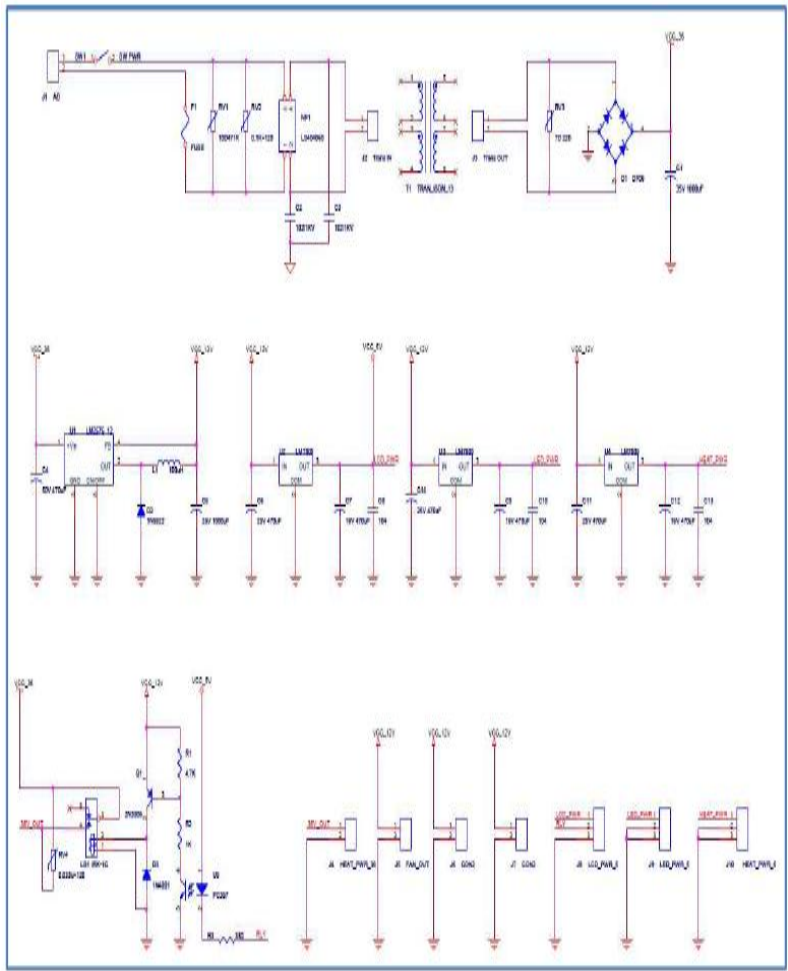

Fig. 5: Digital Perm Power Circuit.

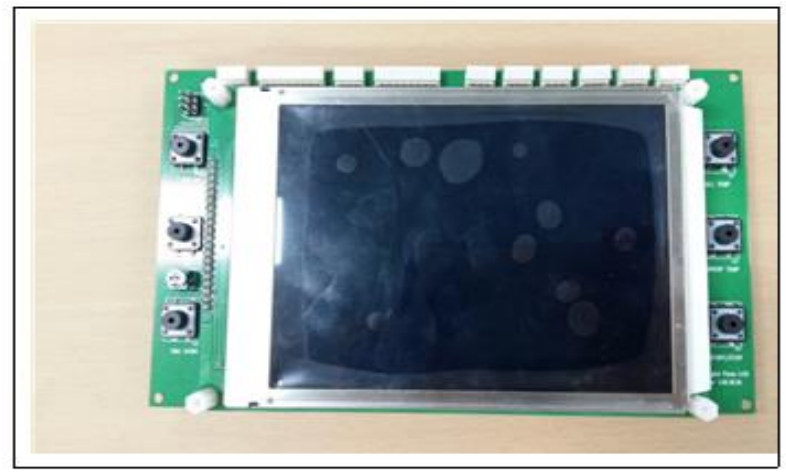

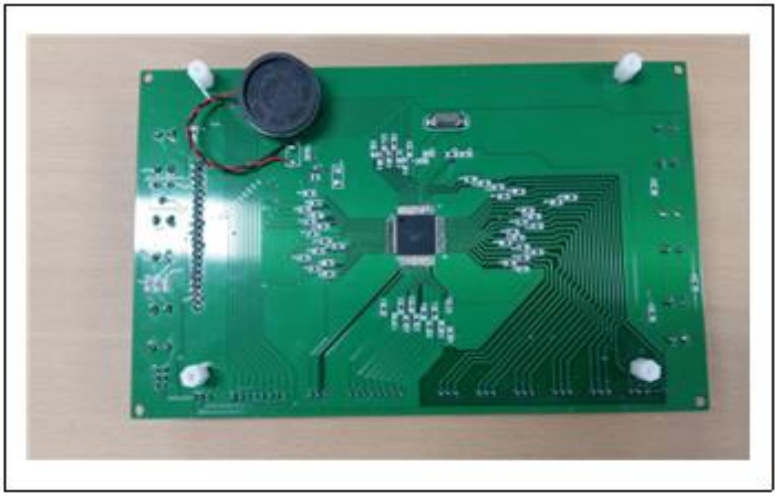

Fig. 6: Results Product.

\subsection{Development of product and design}

Die production having button structure in body and investigation of utilization method for additional function as well as type of design is developed in considering every kind of wiring, speaker, and PCB. Modeling of final product is shown in figure 7.
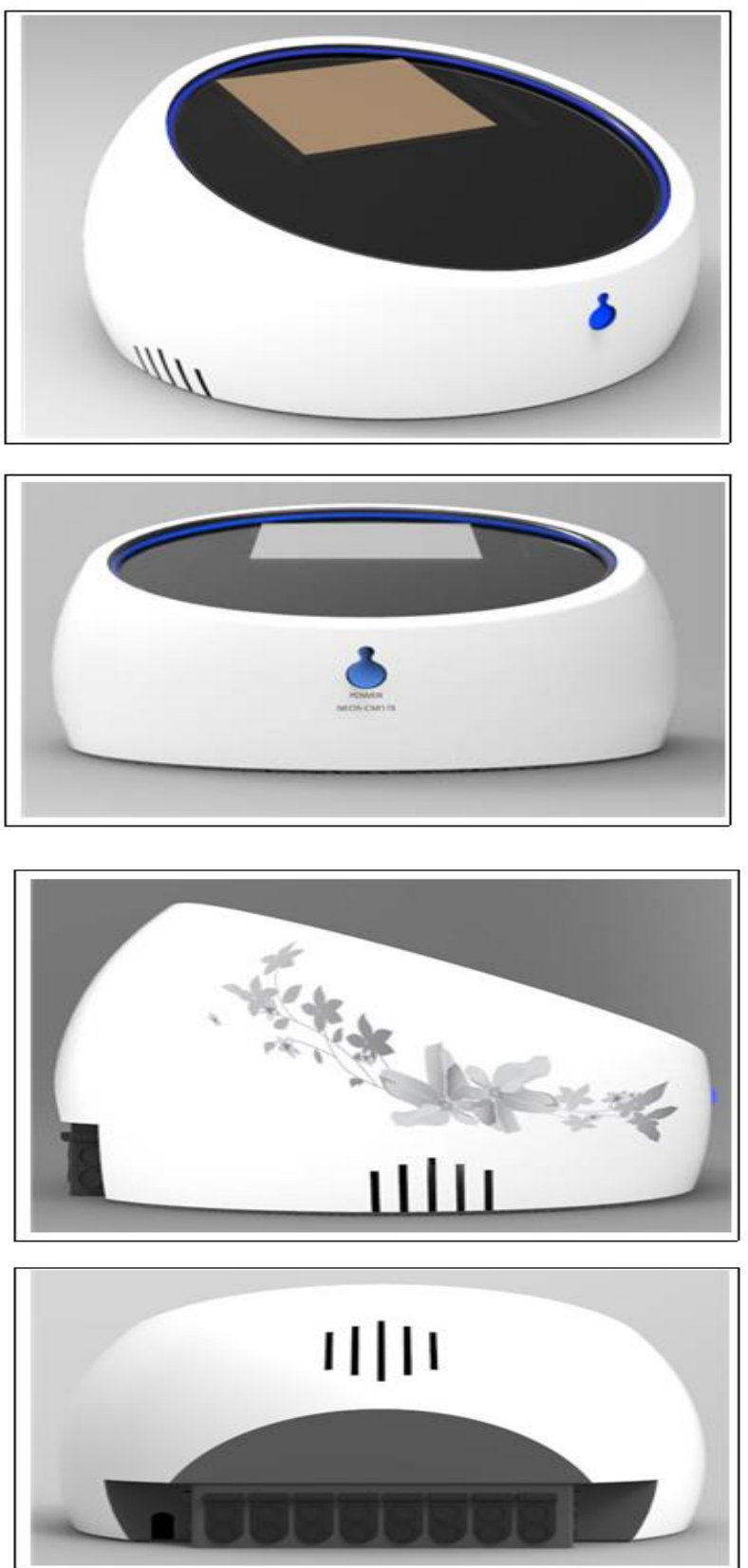

Fig. 7: LCD Display. 


\section{Conclusion}

In order to control heater temperature in the conventional digital perm equipment, the heater sensor to measure internal temperature is installed. Power supply of whole heaters is controlled according to the heating temperature which is detected by temperature sensor. Since the conventional digital perm equipment performs temperature control of the product in all cases, the temperature of each rod can't be controlled even though winding hair condition of rod, amount of permanent wave and hair condition differ from person to person. The performance improvement of digital firm equipment to control temperature in each rod occurred makes it possible to increase convenience as well as effectiveness in this study.

\section{Acknowledgment}

This Study was conducted by research funds from Gwangju University in 2018 , Korea

\section{References}

[1] Ebrahimi, M., Jazayeri, S.A., Design of Digital Controllers for Permanent Magnet Torque Motors, Advanced Materials Research. 2012, 463-464(2), pp. 1219-1223

[2] Wei, J. , Yu, J. , Cheng, Q., Zhu, H. , Yang, Z., Digital Control Technology of Bearingless Permanent Magnet Synchronous Motor, LECTURE NOTES IN ELECTRICAL ENGINEERING. 2011, 87(-), pp. 415-422.

[3] Han, Sanghyun, Hyun, Seung-Jae, Kim, Ki-Jeong, Jahng, Tae-Ahn, Lee, Subum, Rhim, Seung-Chul, Rod stiffness as a risk factor of proximal junctional kyphosis after adult spinal deformity surgery: comparative study between cobalt chrome multiple-rod constructs and titanium alloy two-rod constructs, SPINE JOURNAL. 2017, 17(7), pp. 962-968

[4] Chang, C. J. , Lee, Y. H. , Chen, H. L. , Chiang, C. H. , Hsu, H. F. , Ho, C. C. , Su, W. F. , Dai, C. A., Effect of rod-rod interaction on self-assembly behavior of $\mathrm{ABC}$ p-conjugated rod-coil-coil triblock copolymers, SOFT MATTER. 2011, 7(22), pp. 10951-10960.

[5] Iraola, U. , Aizpuru, I. , Gorrotxategi, L. , Canales Segade, J.M. Etxeberria Larrazabal, A. , Gil, I., Influence of Voltage Balancing on the Temperature Distribution of a Li-Ion Battery Module, IEEE transactions on energy conversion. 2015, 30(2), pp. 507-514.

[6] Krasil'shchikov, V. V., Shutov, A. V., Distribution of points of onedimensional quasilattices with respect to a variable module, Russian mathematics. 2012, 56(3), pp. 14-19.

[7] Devatkal, Suresh K. , Jaiswal, Pranita , Kaur, Amanpreet , Juneja, Vijay, Inactivation of Bacillus cereus and Salmonella entericaserovar typhimurium by Aqueous Ozone: Modeling and UV-Vis Spectroscopic Analysis, OZONE SCIENCE AND ENGINEERING. 2016, 38(2), pp. 124-132.

[8] Ben Hmida, Sarra, Ladhari, Neji, Study of Parameters Affecting Dry and Wet Ozone Bleaching of Denim Fabric, OZONE SCIENCE AND ENGINEERING, 2016, 38(2), pp. 175-180.

[9] Beschi, M., Visioli, A., Berenguel, M. , Yebra, L. J., Constrained Temperature Control of a Solar Furnace, IEEE transactions on control systems technology. 2012, 20(5), pp. 1263-1274.

[10] Pongam, T. , Srisertpol, J. , Khompis, V., PI Controller Design for Temperature Control of Reheating Furnace Walking Hearth Type in Setting up Process, Advanced Materials Research. 2013, 748(-), pp. 801. 